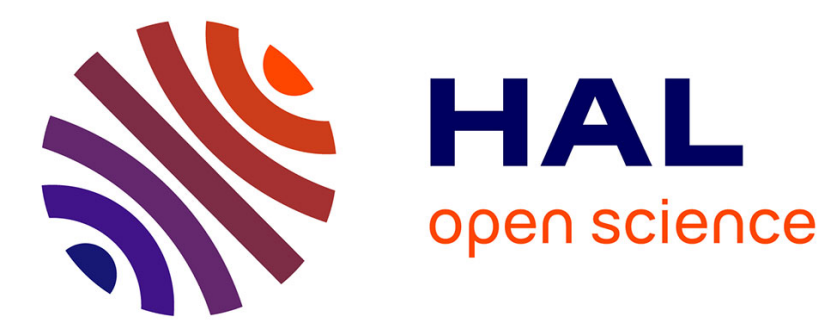

\title{
Robustness of the encouragement design in a two-treatment randomized control trial
}

\author{
Luc Behaghel, Bruno Crépon, Marc Gurgand
}

\section{To cite this version:}

Luc Behaghel, Bruno Crépon, Marc Gurgand. Robustness of the encouragement design in a twotreatment randomized control trial. 2013. halshs-00834169

\section{HAL Id: halshs-00834169 \\ https://shs.hal.science/halshs-00834169}

Preprint submitted on 14 Jun 2013

HAL is a multi-disciplinary open access archive for the deposit and dissemination of scientific research documents, whether they are published or not. The documents may come from teaching and research institutions in France or abroad, or from public or private research centers.
L'archive ouverte pluridisciplinaire HAL, est destinée au dépôt et à la diffusion de documents scientifiques de niveau recherche, publiés ou non, émanant des établissements d'enseignement et de recherche français ou étrangers, des laboratoires publics ou privés. 


\section{PARISSCHOOL OF ECONOMICS}

WORKING PAPER Nº 2013 - 16

Robustness of the encouragement design in a two-treatment randomized control trial

Luc Behaghel

Bruno Crépon

Marc Gurgand

JEL Codes: J64, J68, H44

Keywords: Randomized evaluation; Local Average Treatment Effect; Bounds

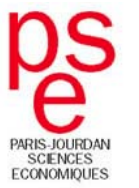




\title{
Robustness of the encouragement design in a two-treatment randomized control trial
}

\author{
L. Behaghel; B. Crépon’ and M. Gurgand ${ }^{\ddagger}$
}

*Paris School of Economics - Inra and Crest

${ }^{\dagger}$ Crest. Corresponding author: CREST - 15, boulevard G. Peri - 92245 Malakoff Cedex France crepon@ensae.fr

${ }^{\ddagger}$ Paris School of Economics - CNRS and Crest 


\title{
Résumé
}

Nous discutons comment le protocole "d'encouragement" à l'entrée en traitement, fréquemment utilisé dans les expérimentations contrôlées par assignation aléatoire peut s'étendre au cas avec deux traitements et un groupe de contrôle. Les conditions requises pour interpréter de façon causale l'estimateur des doubles moindres carrés sont plus fortes que lorsqu'il n'y a qu'un traitement. Un premier cas qui permet l'interprétation causale est celui où l'entrée dans l'un des deux traitements n'est permise qu'à ceux qui ont été assignés à ce traitement. Un second cas est celui où il existe des individus qui entrent dans un traitement quelle que soit leur assignation ("always takers"). Dans ce cas, les taux d'entrée dans un traitement doivent être les mêmes parmi les individus assignés au groupe de contrôle et ceux assignés à l'autre traitement, restriction qu'on peut tester. En cas de rejet, nous montrons que l'effect local du traitement (LATE) peut être borné sous des conditions moins restrictives. Les résultats sont illustrés dans le cadre d'une expérimentation où des demandeurs d'emploi sont orientés de façon aléatoire vers deux programmes d'accompagnement renforcé, l'un public, l'autre privé, ou vers le suivi standard. Codes

JEL: J64, J68, H44

Mots clés: Evaluation par assignation aléatoire, effet local du traitement, bornes

\begin{abstract}
In this paper we discuss how the "encouragement design" used in randomized controlled trials can be extended to a setting with two treatments and one control group. Conditions to interpret the Two-Stage Least Squares (TSLS) estimates causally are stronger than in the case with only one treatment and one control group. A first case where a causal interpretation holds is when only those assigned to one of the two treatments can effectively enter the corresponding program. A second case is when there are always takers. In that second case, entry rates into a given program should be the same among those assigned to the control group and those assigned to the other program; this restriction can be tested from the data. In cases where the restriction is rejected, we derive bounds to the Local Average Treatment Effect (LATE) based on weaker monotonicity conditions. We illustrate the results using data from a large randomized experiment where job seekers at risk of long term unemployment can receive a reinforced counseling scheme offered either by the public or the private sector, or remain on a standard track. JEL Classification:
\end{abstract}

J64, J68, H44

Keywords: Randomized evaluation, Local Average Treatment Effect, Bounds 


\section{Introduction}

The "encouragement design" is frequently used in randomized controlled trials (Duflo et al., 2008). It consists in randomly assigning eligible individuals to two groups and then to "encourage" program participation in one of the two groups usually labeled as "assigned to treatment group". Reduced form and two-stage least squares (TSLS) estimations can then be performed to estimate the Intention-to-treat (ITT) and Local Average Treatment Effects (LATE) parameters, respectively. The LATE parameter can be interpreted as the average effect of the treatment over the specific population of those who entered thanks to the encouragement, as long as the monotonicity condition holds (Angrist and Imbens, 1994). The encouragement design is quite flexible, as it does not require to force anyone to participate in a program or to prevent anyone from participating. This can also be viewed as a robustness property: even if some difference existed between the scheduled entry process and what occurred in practice, as long as randomization occurred in the initial assignment of eligible individuals, the LATE can still be interpreted as an average treatment effect parameter over a population of compliers, although it may differ from the group initially targeted by the program.

However it is frequently the case that more than one treatment group is considered. We consider the questions raised by the encouragement design in that context. Is it still possible to use it, and what conditions are required concerning entry into the programs? A related question has to do with the robustness of randomized controlled trials (RCTs) in that context. Is it still the case that TSLS estimates using assignment to treatment as instruments for program participation can be given a causal interpretation, even in cases where the scheduled entry process was not enforced?

In this paper we show that the encouragement design can still identify a well defined parameter when there are two treatments and one control situation, under a condition that extends and strengthens the monotonicity assumption compared to the one treatment case. This hypothesis is directly testable. Using assumptions inspired by Lee (2009), we show that is is possible to bound the effect under a softer form of monotonicity.

We present in section 2 the framework used to address these issues. Bounds are derived in section 3 . We then apply this framework in section 4 to the case of a large randomized experiment were job seekers at risk of long term unemployment were assigned to a reinforced counseling scheme produced by either private contractor or by the Public Employment Service (the two treatments), or to a standard track. 


\section{Interpretation of 2SLS in the three-treatment case}

There are three treatments $T \in\{0,1,2\}$ and people can be assigned to three groups $Z \in\{0,1,2\}$. Consider a variable of interest $Y$. Denote $\mathbb{1}$ the indicator function; for instance $\mathbb{1}(T=1)$ is the indicator variable for entering treatment 1 .

The issue is how to interpret the TSLS estimates of equation

$$
Y=a+c_{1} \mathbb{1}(T=1)+c_{2} \mathbb{1}(T=2)+u
$$

using $Z_{1}=\mathbb{1}(Z=1)$ and $Z_{2}=\mathbb{1}(Z=2)$ as instruments. Or, equivalently, how to interpret $c_{1}$ and $c_{2}$ as characterized by moment conditions

$$
E[u]=E\left[Z_{1} u\right]=E\left[Z_{2} u\right]=0 .
$$

Following Angrist and Imbens, there are nine potential outcomes in this setting: $Y(t, z)(t, z) \in$ $\{0,1,2\} \times\{0,1,2\}$. As in the LATE framework we introduce program entry decisions under assignment to $z: T(z)$. Two assumptions of the LATE framework directly extend to this setting:

Assumption 1 Exclusion $Y(t, z)=Y(t)$ for all $t, z$

and

Assumption 2 Independence $Y(0), Y(1), Y(2), T(0), T(1), T(2) \perp Z$

We make a somewhat different Monotonicity Assumption than in the two treatment case:

\section{Assumption 3 Extended monotonicity}

$$
\mathbb{1}(T(2)=1)=\mathbb{1}(T(0)=1) \leq \mathbb{1}(T(1)=1)
$$

and

$$
\mathbb{1}(T(1)=2)=\mathbb{1}(T(0)=2) \leq \mathbb{1}(T(2)=2) .
$$

Assumption 3 implies that there are no "defiers" (who would enter treatment $k$ when assigned to group $j \neq k$, but not when assigned to group $k$ ). It also implies that those who enter treatment $k$ when assigned to group $j \neq k$ are exactly those who enter treatment 
$k$ when assigned to the third remaining group. For the assumption to hold, it is enough that the population contains only the following six types:

- never takers, such that: $T(0)=0, T(1)=0, T(2)=0$

- program 1 always takers: $T(0)=1, T(1)=1, T(2)=1$

- program 2 always takers: $T(0)=2, T(1)=2, T(2)=2$

- compliers: $T(0)=0, T(1)=1, T(2)=2$

- program 1 exclusive takers: $T(0)=0, T(1)=1, T(2)=0$

- program 2 exclusive takers: $T(0)=0, T(1)=0, T(2)=1$

Proposition 1 Under Assumption 1 , 2 and 3 ,

$$
c_{1}=E[y(1)-y(0) \mid \mathbb{1}(T(1)=1)-\mathbb{1}(T(0)=1)=1]
$$

and

$$
c_{2}=E[y(2)-y(0) \mid \mathbb{1}(T(2)=2)-\mathbb{1}(T(0)=2)=1] .
$$

$c_{1}$ and $c_{2}$ can thus be interpreted as Local Average Treatment Effects on compliers and program 1 exclusive takers (i.e. compliers to program 1), and on compliers and program 2 exclusive takers (i.e. compliers to program 2), respectively.

\section{Proof 1 See appendix}

Not all the entry patterns are consistent with assumption 3. A first case is the constrained case were the population entering a program only comes from the population who was assigned to it. However instrumental variable parameters can still receive a causal interpretation in another, more flexible entry pattern. It corresponds to the case where always program 1 takers or always program 2 takers exist in the population. This allows that some individuals assigned to the control group enter one program and also that some individuals assigned to one program enter another program. However, there is a restriction for the realized entry process to be consistent with entry process allowing a causal interpretation of the instrumental variable parameters. Indeed $\mathbb{1}(T(1)=2)=\mathbb{1}(T(0)=2)$ and $\mathbb{1}(T(2)=1)=\mathbb{1}(T(0)=1)$ imply that the following testable restriction holds

$$
\begin{aligned}
& \operatorname{Pr}(T=2 \mid Z=1)=\operatorname{Pr}(T=2 \mid Z=0) \\
& \operatorname{Pr}(T=1 \mid Z=0)=\operatorname{Pr}(T=1 \mid Z=2)
\end{aligned}
$$




\section{Bounding Local average treatment Effects}

When the previous assumption 3 does not hold, and for example the testable resctriction 1 has been rejected, instrumental variable parameters cannot be given a causal interpretation in the Rubin Causal model unless constant treatment effects are assumed. It is useful to provide bounds to the LATE in this case.

We consider here a softened extended monotonicity condition:

Assumption 4 Softened extended monotonicity ${ }^{1}$

$$
\mathbb{1}(T(0)=1) \leq \mathbb{1}(T(2)=1) \leq \mathbb{1}(T(1)=1)
$$

and

$$
\mathbb{1}(T(0)=2) \leq \mathbb{1}(T(1)=2) \leq(T(2)=2) .
$$

Proposition 2 Assuming softened extended monotonicity condition 4 holds, then the Local Average Treatment Effect Late $_{j}=E(Y(j)-Y(0) \mid \mathbb{1}(T(j)=1)-\mathbb{1}(T(0)=1)=1)$ can be bounded by

$$
\left(\text { Itt }_{j}-M_{k} \pi_{k}\right) / P_{j} \leq \text { Late }_{j} \leq\left(\text { Itt }_{j}-m_{k} \pi_{k}\right) / P_{j}
$$

where $I_{t}{ }_{j}$ is the Intention-to-treat estimates for assignment to program $j, P_{j}=\operatorname{Pr}(T=$ $j \mid Z=j)-\operatorname{Pr}(T=j \mid Z=0)$ is the proportion of compliers with respect to treatment $j$, $\pi_{k}=\operatorname{Pr}(T=k \mid Z=j)-\operatorname{Pr}(T=k \mid Z=0)$ and $m_{k}$ and $M_{k}$ are bounds on the unobserved effect $E(Y(k)-Y(0) \mid \mathbb{1}(T(j)=k)-\mathbb{1}(T(0)=k)=1)$. When $Y$ has a bounded support $(\underline{Y} \leq Y \leq \bar{Y})$, bounds on $E(Y(k)-Y(0) \mid \mathbb{1}(T(j)=k)-\mathbb{1}(T(0)=k)=1)$ are given by $m_{k}=\underline{Y}-\bar{Y}$ and $M_{k}=\bar{Y}-\underline{Y}$.

\section{Proof 2 See appendix}

\section{Application}

To illustrate the previous results, we use data from a large randomized experiment designed to evaluate the respective efficiency of reinforced counseling scheme provided by private contractor and the Public Employment Service. The experiment took place in France. Results are detailed in Behaghel et al. (2013).

The population enrolled in the experiment was very large. Randomization was used to create three experimental groups: the control group, assigned to the usual track (without

\footnotetext{
${ }^{1}$ We could indifferently consider conditions of the form $\mathbb{1}(T(2)=1) \leq \mathbb{1}(T(0)=1) \leq \mathbb{1}(T(1)=1)$
} 
intensive counseling), and two treatment groups (assigned to the public program or assigned to the private program). The randomization took place during the first interview at the local ANPE office (that is to say, when first registering as unemployed). Once the caseworker had assessed the job seeker's eligibility, he ran an application on an Extranet to randomly assign her to treatment 1 (public program), treatment 2 (private program) or to the control group (usual track).

The design was an encouragement design. After this randomization, the employment service agent told the job seeker which track he was being offered. The job seeker was however free to refuse the more intensive tracks. Depending on the assignment and on his decision during the first interview, he was subsequently contacted by PES staff for the usual track, by a dedicated caseworker from the PES-provided intensive program, or by one of the private firms providing the service. Job seekers of the two treatment groups entered the program they were assigned to by signing a specific agreement; if they refused to sign, did not show up, or were eventually found not to meet the criteria of the intensive program, they went back to the usual track.

Results are presented in table 1. We consider a binary outcome variable (exit to employment). The table has two panels. The upper panel displays the first stage and the reduced form regressions. The lower panel presents TSLS as well as bounds to the LATEs based on proposition 2. The first column of the upper panel presents the first stage regression for "Entry into the public program" while the second column presents the results for the first stage regression for "Entry into the private program". The scheduled entry process was to assign individuals to treatment groups and a control group and that job seekers could only enter the reinforced counseling program they were assigned to. Clearly, looking at the table this scheduled entry process was not respected. There are job-seekers assigned to the control group that entered the private program (2.9\%) or the public program $(0.4 \%)$. Similarly there are job seekers assigned to the private program entering the public program $(0.5 \%)$ and job seekers assigned to the public program entering the private program $(2.1 \%)$. One reason for non compliance with the scheduled entry process was that private operators wanted to maximize the number of job seekers they would enroll, as they received a large upfront payment per enrolled job seeker (900 euros). Therefore, they put pressure on local PES staff to send them job seekers. Although it was scheduled that job seekers entering the experiment had to be first received in an interview, be identified by a PES caseworker as eligible for the experiment and then be randomly assigned to the different groups, this pressure had the effect that some job seekers were sent to the private contractors outside of experiment (simply picking their names from the unemployment 
records); this could be in conflict with their assignment in the experiment, if they had been in parallel randomly assigned to the public program or to the control group.

Even if the realized entry pattern does not perfectly fit with the scheduled entry, it can still be consistent with a causal interpretation of the parameters as LATE. This is the case if the same proportion of job seekers enters a given program when assigned to the control group as when assigned to the other program. This can be tested. The line "pvalue extended monotonicity" in table 1 reports the corresponding results. The restriction is not rejected for the public program, but it is rejected for the private program. This means that for the public program we have to consider bounds for the LATE while for the private program the TSLS estimates can be directly considered.

The lower part of the table presents TSLS estimates as well as estimated lower and upper bounds. The TSLS estimates for the public and the private programs are strongly different, $10.2 \%$ for the public program and $4.5 \%$ for the private program. The bounds on the pubic program effect are $7.5 \%$ and $12.5 \%$. The bounds for the private program are closer to each other. It is useful to review the different components leading to the bound. The last column of the upper part of the table gives the ITT estimates which are used to compute the bounds. The bounds on the LATE parameter for one program, say public, then depend in particular on the difference between entry rates into the other program, here private, for job seekers assigned to the public program and job seekers assigned to the control group. For the private program, the difference is $2.9 \%-2.1 \%=0.8 \%$, which determines the width of the interval for the public program LATE. For the public program it is $0.5 \%-0.4 \%=0.1 \%$. The bounds also depend on the impact of assignment to a program on the probability to enter that program. This is about $30 \%$ for the public program and $40 \%$ for the private program. Putting these two elements together gives a factor of $2.6(=0.8 / 0.3)$ for the public program compared to $0.25(=0.1 / 0.4)$ for the private program. The consequences of the violation of the entry schedule are such much more dramatic for the estimation of the public program impact. Last, the bounds to the effect on treatment $j$ depend on the unobserved term $E(Y(k)-Y(0) \mid \mathbb{1}(T(j)=$ $k)-\mathbb{1}(T(0)=k)=1$ ). In the table, we take a conservative approach in the spirit of Horowitz and Manski (2000), and use the fact that this term belongs to $[-1,1]$ as the outcome variable belongs to $\{0,1\}$. This yields a rather wide identified set. Alternatively, if we are interested in the order of magnitude of the bias of the TSLS estimate of the public program impact, we can assume that the unobserved term is of the same order of magnitude as the TSLS estimate of the private program impact (4.5\%); this yields a bias of the order of $0.12 \%(=(0.8 / 0.3) \times 4.5 \%)$, which is quite small compared to the $10.2 \%$ TSLS estimate. 


\section{Conclusion}

In this paper we have discussed how the encouragement design which typically involves a potential treatment group and a potential control group can be extended to a more general setting where more that one potential treatment group exists. We also discuss the robustness property of RCTs in this setting. The results we obtain show that the framework is more constrained with two than with one treatment. In the typical case individuals are assigned to programs or to a control group and they can only enter the program they are assigned to. Another case where TSLS estimates can receive a causal interpretation is when there are always takers for some programs. This implies however that there should be no difference in the entry rate into a given program when assigned to the control group or to the other program; a property that can be tested from the data. If that restriction does not hold, bounds can still be derived under weaker conditions; the width of the identified set depends on the above difference in entry rates.

\section{References}

Angrist, J., G. Imbens and D. Rubin (1996), "Identification of Causal Effects Using Instrumental Variables", Journal of the American Statistical Association, 91(434), pp. 444-455.

Behaghel, L., B. Crepon and M. Gurgand (2013), Private and Public Provision of Counseling to Job-Seekers: Evidence from a Large Controlled Experiment, mimeo.

Duflo E., R. Glennerster and M. Kermer (2008), "Using Randomization in Development Economics Research: A Toolkit" in T. Paul Schultz \& John A. Strauss (ed.), Handbook of Development Economics, Handbook of Development Economics, Elsevier, edition 1, volume 4 , number 5 .

Horowitz, J. and C. Manski (2000), 'Nonparametric analysis of randomized experiments with missing covariate and outcome data', Journal of the American Statistical Association 95(449), $77-84$.

Imbens G. and J.D. Angrist (1994), "Identification and Estimation of Local Average Treatment Effects", Econometrica, Vol. 62, No. 2.

Lee, D. (2009), 'Training, wages, and sample selection: Estimating sharp bounds on treatment effects', Review of Economic Studies 76, 1071-1102. 


\section{Appendix}

\section{Proof of proposition 1}

Given Assumption 1, $Y$ can be written as

$$
Y=Y(0)+\Delta_{1} \mathbb{1}(T=1)+\Delta_{2} \mathbb{1}(T=2) .
$$

where $\Delta_{1}=Y(1)-Y(0)$ and $\Delta_{2}=Y(2)-Y(0)$.

Thus

$$
\begin{aligned}
u & =Y-c_{0}-c_{1} \mathbb{1}(T=1)-c_{2} \mathbb{1}(T=2) \\
& =Y(0)-c_{0}+\left(\Delta_{1}-c_{1}\right) \mathbb{1}(T=1)+\left(\Delta_{2}-c_{2}\right) \mathbb{1}(T=2)
\end{aligned}
$$

We have:

$$
T=T(0)+(T(1)-T(0)) Z_{1}+(T(2)-T(0)) Z_{2}
$$

which leads to

$\mathbb{1}(T=k)=\mathbb{1}(T(0)=k)+(\mathbb{1}(T(1)=k)-\mathbb{1}(T(0)=k)) Z_{1}+(\mathbb{1}(T(2)=k)-\mathbb{1}(T(0)=k)) Z_{2}, \quad k=1,2$

Thus

$$
\begin{aligned}
& u=Y(0)-c_{0}+\left(\Delta_{1}-c_{1}\right) \mathbb{1}(T(0)=1)+\left(\Delta_{2}-c_{2}\right) \mathbb{1}(T(0)=2)+ \\
& Z_{1} \times\left[\left(\Delta_{1}-c_{1}\right)(\mathbb{1}(T(1)=1)-\mathbb{1}(T(0)=1))+\left(\Delta_{2}-c_{2}\right)(\mathbb{1}(T(1)=2)-\mathbb{1}(T(0)=2))\right]+ \\
& Z_{2} \times\left[\left(\Delta_{1}-c_{1}\right)(\mathbb{1}(T(2)=1)-\mathbb{1}(T(0)=1))+\left(\Delta_{2}-c_{2}\right)(\mathbb{1}(T(2)=2)-\mathbb{1}(T(0)=2))\right]
\end{aligned}
$$

The TSLS orthogonality conditions defining $c_{0}, c_{1}$ and $c_{2}$ together with assumption 2 imply

$$
E\left[\left(\Delta_{1}-c_{1}\right)(\mathbb{1}(T(1)=1)-\mathbb{1}(T(0)=1))+\left(\Delta_{2}-c_{2}\right)(\mathbb{1}(T(1)=2)-\mathbb{1}(T(0)=2))\right]=0
$$

and

$$
E\left[\left(\Delta_{1}-c_{1}\right)(\mathbb{1}(T(2)=1)-\mathbb{1}(T(0)=1))+\left(\Delta_{2}-c_{2}\right)(\mathbb{1}(T(2)=2)-\mathbb{1}(T(0)=2))\right]=0
$$

These two equations can be solved in $c_{1}$ and $c_{2}$. Without further assumptions, $c_{k}$ is a 
linear combination of $E\left[\Delta_{l}(\mathbb{1}(T(m)=l)-\mathbb{1}(T(0)=l))\right]$, and $(E[(\mathbb{1}(T(m)=l)-\mathbb{1}(T(0)=$ $l))$ ], which is hard to interpret.

However, assumption 3 implies first that $\mathbb{1}(T(m)=l)-\mathbb{1}(T(0)=l)=0$ for $m \neq l$ and second that $\mathbb{1}(T(m)=m)-\mathbb{1}(T(0)=m) \leq 0$. This leads to

$$
E\left[\left(\Delta_{1}-c_{1}\right)(\mathbb{1}(T(1)=1)-\mathbb{1}(T(0)=1))\right]=0
$$

and

$$
E\left[\left(\Delta_{2}-c_{2}\right)(\mathbb{1}(T(2)=2)-\mathbb{1}(T(0)=2))\right]=0 .
$$

and then to

$$
E\left[\Delta_{1} \mid \mathbb{1}(T(1)=1)-\mathbb{1}(T(0)=1)=1\right]-c_{1}=0
$$

and

$$
E\left[\Delta_{2} \mid \mathbb{1}(T(2)=2)-\mathbb{1}(T(0)=2)=1\right]-c_{2}=0
$$

which yields proposition 1 .

\section{Proof of proposition 2}

Consider for example the case of parameter Late $_{1}$.

The outcome equation can be written as

$$
Y=Y(0)+\Delta_{1} \mathbb{1}(T=1)+\Delta_{2} \mathbb{1}(T=2)
$$

from which we deduce the expression of the Intention-to treat parameters.

For example for $Z=1$, the coefficient $I t t_{1}$ can be written as

$$
\begin{aligned}
\text { Itt }_{1} & =E(Y \mid Z=1)-E(Y \mid Z=0)=E\left(\Delta_{1}(\mathbb{1}(T(1)=1)-\mathbb{1}(T(0)=1))\right) \\
& +E\left(\Delta_{2}(\mathbb{1}(T(1)=2)-\mathbb{1}(T(0)=2))\right) \\
& =\text { Late }_{1} P_{1}+E\left(\Delta_{2} \mid \mathbb{1}(T(1)=2)-\mathbb{1}(T(0)=2)=1\right) \pi_{2},
\end{aligned}
$$

where we use the softened extended monotonicity assumption.

$E\left(\Delta_{2} \mid \mathbb{1}(T(1)=2)-\mathbb{1}(T(0)=2)=1\right)$ is not identified from the data and needs to be bounded. The expression of bounds for $L_{a t e}$ follows directly. 
Table 1: Application to reinforced counseling scheme

\begin{tabular}{|c|c|c|c|}
\hline & Enter public & Enter private & ITT \\
\hline Assigned public & $\begin{array}{c}32.1^{* * *} \\
(0.9)\end{array}$ & $\begin{array}{c}2.1^{* * *} \\
(0.3)\end{array}$ & $\begin{array}{c}3.2^{* * *} \\
(1.2)\end{array}$ \\
\hline Assigned private & $\begin{array}{c}0.5^{* * *} \\
(0.1)\end{array}$ & $\begin{array}{c}42.8^{* * *} \\
(0.4)\end{array}$ & $\begin{array}{l}1.8^{* *} \\
(0.9)\end{array}$ \\
\hline Assigned standard track & $\begin{array}{c}0.4^{* * * *} \\
(0.1)\end{array}$ & $\begin{array}{c}2.9^{* * * *} \\
(0.3)\end{array}$ & \\
\hline \multirow[t]{3}{*}{ p-value extended monotonicity } & 44.3 & 2.7 & \\
\hline & & \multicolumn{2}{|c|}{ LATE } \\
\hline & IV & Lower bound & Upper bound \\
\hline Enter public & $\begin{array}{c}10.2^{* * *} \\
(3.8)\end{array}$ & $\begin{array}{l}7.5^{*} \\
(3.9)\end{array}$ & $\begin{array}{c}12.7^{* * *} \\
(4.0)\end{array}$ \\
\hline Enter private & $\begin{array}{l}4.5^{* *} \\
(2.1)\end{array}$ & $\begin{array}{l}4.3^{*} \\
(2.2)\end{array}$ & $\begin{array}{l}4.8^{* *} \\
(2.2)\end{array}$ \\
\hline control mean & 23.0 & \# Obs & 37,952 \\
\hline
\end{tabular}

Source: Data from Behaghel et al. (2013). The table has two panels. The upper panel provides reduced form results: the first two columns report the results of the first stage regression and the last column provides the Intention-to-treat estimates. The line "p-value extended monotonicity" provides the result of the test for a same proportion of job seekers entering the program when assigned to the control group or the alternative treatment group. The lower panel provides TSLS results and bounds of Local Average Treatment Effects corresponding to equation (2). Robust standard errors in parenthesis. 